\title{
Health and Ease of Doing Business Indices in the Eastern Mediterranean Region Based on the Panel Data
}

\author{
Mohammad Veisi and Fereshteh Karimi*
}

$\mathrm{PhD}$ Student in Health Economics, Department of Management Sciences and Health Economics, School of Public Health, Tehran University of Medical Sciences, Tehran, Iran.

\section{*Corresponding Author: \\ xfereshtek69@gmail.com}

Received: 15 May, 2021

Accepted: 30 June, 2021

Published: 30 July, 2021

\begin{abstract}
This study aimed to investigate the relationship between ease of doing business and health indices in the Eastern Mediterranean Region. The present study is a panel data study which was done using data from 2007 to 2019. Pre-estimation and post-estimation tests were performed to estimate the model by data panel model. The tests included the unit root test, Fisher test and Hausman test, crosssectional dependence tests, co-integration test, test for heteroscedastic and autocorrelation test between disturbances. The data were entered into EVIEWS-7 and STATA-13 software and the final estimation of the model was done by Driscoll and Croy method. Levin-Lin-Chu (LLC) test, Im-Pesaran-Shin test and Shin tests showed that most of the variables were significant. The panel effects were confirmed based on the Limer test $(\mathrm{F}=99.155, \mathrm{P}<0 / 001)$. Hausmann test rejected the random effects in the model and showed fixed effects $\left(\chi^{2}=78.2968\right.$, $\mathrm{P}<0 / 001)$. The results of the parent test showed a cross-sectional dependence of the disturbances. The Cao co-integration test also confirmed the existence of coaccumulation $(\mathrm{P}<0.001, \mathrm{t}=-4.38)$. The null hypothesis of this test based on variance homogeneity was rejected $(\mathrm{P}<0.001, \chi 2=78.2968)$. The final estimation shows $68 \%$ the model determination coefficient based on the Driscoll and Croy test; This means that $68 \%$ of the variables dependent on the explanatory variables of this model are explained. The ease of doing business index has had a significant impact on determining health. Therefore, health managers and decision makers should pay attention to the ease of doing business index on the health of communities in determining their general health policies. On the other hand, they should improve the inter-section cooperation with the aim of improving the employment situation to achieve the general goal of health in the communities.
\end{abstract}

Keywords: Ease of doing business, Life expectancy, Panel data, Health, The Eastern Mediterranean Region

\section{Introduction}

One of the most important issues in the individuals' lives and communities is the issue of work and activity that leads to production and has been targeted as the most important selected topic in the 2019 Global Development Report [1]. Work and activity can be affected by the individuals' health or affect the health of individuals and communities. In general, it can be said that there is a two-way relationship between health and work in different societies. Improper work and poor work conditions may affect the employees' health
[2]. The health affects the employees' efficiency. A study has shown that the loss of ultimate time efficiency per week in patients with diabetes mellitus is on average $0.56 \%$ higher than normal people [3]. Healthy people are encouraged to work less, have more life expectancy, have more fun, have less fatigue and have more motivation to do work, and as a result have more efficiency. People's health indirectly affects their easier learning, and this makes things happen faster and activities that lead to production and economic development accelerate $[4,5]$. On the other hand, the 
business situation in the communities can also be an explanatory factor for the health status of the communities. High work hours can lead to heart disease or sudden death from heart disorders. Incompatible work conditions can also lead to mental disorders and suicide $[6,7]$. Prolonged work hours have a negative effect on obesity and smoking and reduce the sleep time and quality [6]. Therefore, it can be said that there is a two-way relationship between people's health and business situation [8]. Appropriate business status can be associated with less stress, higher job satisfaction, a happier mental state, and better overall health resulting in productivity [9]. Therefore, considering the relationship between work and health, it should be examined whether there is a relationship between health and business indices, and if so, what is its severity and form!?

Employment usually means gaining sufficient economic resources, which is necessary for material well-being and full participation in today's society. Material wellbeing is one of the dimensions of health that is determined by patterns of income, consumption or wealth and assets. Work can determine the mental needs of communities on this issue; In this way it is related to the mental health of communities. In some societies, work can be centered on the personality, city, rank, and social status of individuals. Employment and socio-economic variables are major causes of mortality, mental health and physical health. Besides, unemployment, re-employment and the employment situation in general affect the health of individuals and society [10]. The World Bank publishes data on the ease of doing business, then given the context, we decided to examine the relationship between health and business indices in the countries of the Eastern Mediterranean Region.

\section{Materials and Methods}

The present study is a panel data study. The analysis of this study is based on data from 2007 to 2019. Today, the use of panel data has expanded significantly in econometric studies. In this type of study, it is possible to examine issues that normally cannot be investigated using time series and cross-sectional data. Advantages of the panel include more information, wider variety, more variability, less alignment, higher degree of freedom and lower bias. It can also be said that since in this type of study, the variables are examined as a process, the dynamics of the variables are considered. The purpose of this study is to investigate the existence or absence of a relationship between health and ease of doing business indices. This study analyzes the archived data related to the mentioned years in the Eastern Mediterranean Region (EMRO). The data of this study include data related to the ease of doing business indices and data related to selected health indices. The data needed to conduct the present study were extracted from international organizations such as the World Health Organization, the World Bank, and the Global Burden of Disease (GBD). Unavailable data were estimated based on processes, country rankings, and coefficients obtained. The ease of doing business indices were reported annually by the World Bank. According to the World Bank, the following variables are defined as the ease of doing business indices [10].

- Starting a business

- Dealing with construction permits

- Getting electricity

- Registering property

- Getting credit

- Protecting minority investors

- Paying taxes

- Trading across borders

- Enforcing contracts

- Resolving insolvency

Life expectancy at birth was considered as a dependent variable and the ease of doing business variable was considered as explanatory variables; Then the econometric model of this study is as follows.

Log life $\exp ^{1}=\mathrm{C}+\mathrm{a} 1 \log$ Start1it + a2 Log Deal2it + a3 Log Elect3it + a4 Log Regist4it + a5 Log Credit5it + a6Log Invest6it + a 7 Log Tax7it + a8 Log Trade8it + a9 Log Enforce9it + a10 Log Resolve10it + uit

Log life exp: Life expectancy at birth algorithm in each country between 2007 and 2019

Log Start ${ }_{1 i t}$ Index score algorithm (start a business) in each country between 2007 and 2019

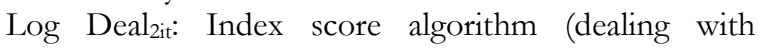
construction permits) in each country between 2007 and 2019

Log Elect $3 \mathrm{it}$ : Index score algorithm (getting electricity) in each country between 2007 and 2019

Log Regist 4it $_{\text {: }}$ Index score algorithm (registering property) in each country between 2007 and 2019

Log Credit 5 it: Index score algorithm (getting credit) in each country between 2007 and 2019

Log Invest 6 it: Index score algorithm (protecting minority investors) in each country between 2007 and 2019

Log Tax $_{7 \text { it: }}$ Index score algorithm (paying taxes) in each country between 2007 and 2019

Log Trade 8it: Index score algorithm (trading across borders) in each country between 2007 and 2019

Log Enforce 9it $_{\text {: }}$ Index score algorithm (enforcing contracts) in each country between 2007 and 2019

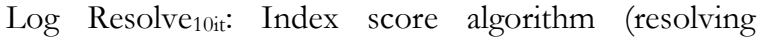
insolvency) in each country between 2007 and 2019

$\mathrm{U}_{\mathrm{it}}$ : Model disturbance component

In this study, data on independent and dependent variables were collected from the World Bank and the World Health Organization over 2007-2019. Various 
tests were performed to estimate the model based on the data panel. These tests were divided into two categories of pre- estimation and post- estimation tests of the initial model. First, according to Hausman test and determining the type of model, the fixed or random effects of the initial model were estimated and post-estimation tests were performed based on that, and the final estimation of the model would be decided. Pre-estimation tests in this study included unit root test, Fisher test and Hausman test. Cross-sectional dependence tests, cointegration test, test for heteroscedastic and autocorrelation test between disturbances were the tests that determined the final type of estimation model after initial estimation. In this study, the data were entered into the software EVIEWS-7 and STATA-13 software and the final estimation of the model was done by Driscoll and Croy method.

\section{Findings}

The first test in estimating the model was to measure the significance of the variables. The unit root test, Levin-Lin-Chu test, and Im-Pesaran-Shin test were performed to determine the variability of the study variables. The null hypothesis of these tests was that the variable has a unite root. According to this hypothesis and based on the results of Levin-Lin-Chu test, all variables except "paying taxes" were significant. The results of Im-Pesaran-Shin test also showed that the only "resolving insolvency" variable was insignificant. The results of unit root tests are presented in Table 1.

Table 1

Results of unit root tests.

\begin{tabular}{lll}
\hline Test variables & Levin-Lin-Chu & Im-Pesaran-Shin \\
\hline Starting a business & $43 / 7[0 / 000]$ & $-2 / 60[0 / 004]$ \\
Dealing with construction permits & $5 / 67[1 / 00]$ & $-2 / 44[0 / 000]$ \\
Getting electricity & $-2 / 02[0 / 021]$ & $-2 / 66[0 / 003]$ \\
Registering property & $-1 / 85[0 / 031]$ & $-2 / 41[0 / 007]$ \\
Getting credit & $-9 / 25[0 / 000]$ & $-2 / 67[0 / 000]$ \\
Protecting Minority investors & $-3 / 03[0 / 001]$ & $-1 / 87[0 / 03]$ \\
Paying taxes & $229 / 87[1 / 000]$ & $-2 / 97[0 / 001]$ \\
enforcing contracts & $-2 / 86[0 / 002]$ & $-2 / 189[0 / 00]$ \\
Resolving insolvency & $-1 / 68[0 / 046]$ & $-1 / 55[0 / 1]$ \\
Trading across borders & $-3 / 57[0 / 00]$ & $-3 / 66[0 / 00]$ \\
\hline
\end{tabular}

After determining the significance of the variables, the Limer test was performed to determine the mixed or panel effects. The null hypothesis of this test is the existence of mixed effects. The results of this test showed that the null hypothesis was rejected and the panel effects was confirmed $(\mathrm{P}<0.001, \mathrm{~F}=155.99)$. Hausman test was performed after determining the panel effects to determine the initial estimation of the model and performing pre-estimation tests. The null hypothesis of the Hausman test are the existence of random effects and the rejection of the fixed effects in estimating the model. The results of this test showed that the existence of random effects in the model is rejected and fixed effects was confirmed $(\mathrm{P}<0.001$, $\left.\chi^{2}=-3.87\right)$. In the following, the model is estimated by random effects method. After estimating the model by random method, Hashem Pesaran cross-sectional dependence tests, Wald heterogeneity of variance test, Cao cointegration test and Wooldridge autocorrelation test were performed on the disturbances. The results of the Wald test showed that the null hypothesis of the test based on the existence of cross-sectional dependence, was not rejected $\left(\mathrm{P}<0.006, \chi^{2}=9.374\right)$. Therefore, the disturbances in this study had crosssectional dependence, and for the final determination of the model, cross-sectional dependence problem must be solved. The results of Cao cointegration test showed that the null hypothesis of the test based on the absence of coaccumulation was rejected and the existence of coaccumulation was determined ( $\mathrm{P}<0.001$, $\mathrm{t}=-4.38)$. The result of the Wald test showed that there is variance inequality in the disturbances of this model. The null hypothesis of this test based on variance homogeneity was rejected $\left(\mathrm{P}<0.001, \chi^{2}=2968.78\right)$. After performing the above tests and confirming the existence and autocorrelation, variance inequality and cross-sectional dependence between the disturbances, a model should be selected to solve the problems in the final estimation of the coefficients. XTSCC code was run to in the software to perform the Driscoll and Croy test for finalizing the model and solve the above problems. The final estimation results are presented in Table 2. The table below shows the coefficients are the same elasticities because the information was entered into the software in a logarithmic way for estimating the model. This means that one percent change in each of the explanatory variables represents the percentage of changes in the dependent variable, i.e., life expectancy at birth. Trading across borders and Registering property variables were not significant and 
were not considered in the final model. The determination coefficient of model was $64 \%$. This means that $64 \%$ of the dependent variable changes are explained by the explanatory variables of this model and the independent variables were able to show $64 \%$ of the dependent variable changes correctly. In general, the model was significant at the level of 0.05 .

Table 2

The results of the final estimation of the model by Driscoll and Croy method.

\begin{tabular}{|c|c|c|c|c|}
\hline Variables & Coefficient & Standard error & Probability & Statistics $\mathrm{t}$ \\
\hline Fixed component & $1 / 486$ & $0 / 026$ & $<0 / 00$ & $55 / 38$ \\
\hline Starting a business & $0 / 795$ & $0 / 009$ & $<0 / 00$ & $8 / 19$ \\
\hline Dealing with construction permits & $-0 / 02$ & $0 / 007$ & $0 / 017$ & $-2 / 74$ \\
\hline Getting electricity & $0 / 06$ & $0 / 005$ & $<0 / 00$ & $11 / 34$ \\
\hline Getting credit & $0 / 032$ & $0 / 005$ & $<0 / 00$ & $5 / 73$ \\
\hline Protecting Minority investors & $-0 / 016$ & $0 / 025$ & $0 / 05$ & $-0 / 63$ \\
\hline Paying taxes & $0 / 0418$ & $0 / 014$ & $0 / 014$ & $2 / 84$ \\
\hline enforcing contracts & $0 / 0262$ & $0 / 009$ & $0 / 019$ & $2 / 69$ \\
\hline Resolving insolvency & $0 / 012$ & $0 / 009$ & $0 / 05$ & $2 / 07$ \\
\hline $\begin{array}{l}\text { Determination coefficient } \\
\text { (R-squared) }=\% 64\end{array}$ & & $\begin{array}{c}\text { Probability } \\
0 / 00=\end{array}$ & & \\
\hline
\end{tabular}

\section{Conclusion}

Business activity is a factor for production and also one of the social determinants of health [8]. Every year, the World Bank presents indices from around the world as the indices of the ease of doing business. These indices determine how simple and accessible it is to start and continue the business [11]. It can be said that these indices as prerequisites for facilitating business and activity can determine the right and appropriate employment rate with income and satisfactory conditions for individuals and communities. Therefore, considering that work and proper activity and employment are known as one of the determinants of health, it can be hypothesized that the ease of doing business can be a predictor in determining the health to some extent. Considering that the ease of doing business indices determined by the World Bank are reported every year, we collected the relevant data and examined the relationship between these indices and the health index of the studied communities in the countries of the Eastern Mediterranean Region. For this purpose, according to the type of data studied which was the relationship between the ease of doing business indices and health index in the countries of the region, and each of these items were variable, we performed the analysis through the panel method. Before entering our data panel model into the software, we performed the prerequisite tests and made sure that the data was panel. Data panel analysis allows us to mix the different dimensions and variables, including crosssectional data and time series [12]. In this way, we mixed the health variable, the variable of the countries in the region and each of the variables of business indices in the form of a panel. In general, the panel method was the best one to get the results regarding to the properties of the study variables [13]. Weakness in health and weakness in its promotional mechanisms have been associated with physical weakness, psychological problems hindering activity and production, poverty and ultimately reduced economic development [14]. On the other hand, it has been found that health and health care can lead to economic development and thus improve working conditions through higher productivity and more motivation of the workforce [5]. Can improving working conditions and ease of doing business also affect the health of communities? It should be noted that the health is not determined only by health systems and services and there are other factors involved in determining health that are far more important than the total activities of the health system. In fact, the conceptual framework set by the World Health Organization implies that human living conditions affect their health. According to this framework, factors such as governance, macroeconomic policies, social policies, public policies and social and cultural values are effective in determining the health [15]. The health system services make up only 10 percent of the determinants of health, however it is noted that social determinants of health determine more than $20 \%$ of the health of communities [16]. In a report, Healthy People 2020 identified the health determinants including the policy, social determinants, health care services, individual and biology behaviors and genetics [17]. One of the most important determinants of health in this report is the employment status, work and activities and job opportunities in the community that can significantly affect the health of individuals and communities [1715]. The World Health Organization (WHO) has reported the social and economic benefits of the ease of doing business including the increase of the wealth 
of people living in the area and reducing carbon pollution due to the lack of travel needed to work. Paying attention to the business of the communities through the managers and health officials is also mentioned as a positive point [18]. Therefore, through data published by the World Bank and the World Health Organization, we tested our hypothesis, that is, the relationship between the ease of doing business indices and the health index.

Unemployment can even cause temporary health problems such as anger, frustration, depression, increased effort, feelings of futility, and poor mental health [19]. Unemployed people are more likely to face tensions that lead to death. In some studies unemployment, poverty, and disease are introduced as a cycle. Therefore, providing better conditions for getting a job or at least reducing the psychological effects of unemployment has become a necessity in all societies. The psychosocial work environment may also affect people's health. Responsibility and dealing with multiple tasks may lead to stress and cardiovascular disease. Proper work can guarantee psychological security for the family or even the community and reduce stress; In contrast, poor working conditions may expose the person to illness [20,21]. The ease of doing business can cover these cases and therefore the effect of the ease of doing business indices on health was positive and significant. The present study is the first to examine the effect of business indices on health. The test of the effect of ease of doing business indices published by the World Bank on health indicates a positive and significant effect of these indices on health. In general, the health index is determined 64\% by the ease of doing business indices. This rate shows that the ease of doing business indices have a significant effect on determining the health. Therefore, health managers and decision makers should pay attention to the ease of doing business indices on the health of communities in determining general health policies, their goals for improving health status, etc. The health systems should increase their cross-sectoral cooperation to achieve the overall health goal in communities and improve the ease of doing business in communities; Because the employment status and ease of doing business can be effective in determining a significant part of community health.

\section{Acknowledgments}

The present study was conducted using the information available on the website of the World Health Organization and the World Bank. The researchers of the study are grateful to the esteemed judges who helped to improve the quality of the paper with their valuable comments.

\section{References}

1. GROUP WB. World development report 2019: The changing nature of work: World Bank; 2018.

2. Katzmarzyk PT, Church TS, Craig CL, Bouchard C. Sitting time and mortality from all causes, cardiovascular disease, and cancer. Med Sci Sport Exerc. 2009; 41(5): 998-1005.

3. Tabano DC, Anderson ML, Ritzwoller DP, Beck A, Carroll N, Fishman PA. et al. Estimating the impact of diabetes mellitus on worker productivity using selfreport, electronic health record and human resource data. J Occup Environ Med. 2018; 60(11): e569-e74.

4. Sammut A. Assessing the relationship between health and economic growth: Malta's case: University of Malta; 2013.

5. Husain MJ. Contribution of health to economic development: A survey and overview. Economics: The Open-Access, Open-Assess E-J. 2010; 4(14): 1-52.

6. Okamoto S. Hours of work and health in Japan. Ann Epidemiol. 2019; 33: 64-71.

7. Takahashi M. Sociomedical problems of overworkrelated deaths and disorders in Japan. J Occup Health. 2019; 61(4): 269-277.

8. Marmot M, Friel S, Bell R, Houweling TA, Taylor S. Health CoSDo. Closing the gap in a generation: health equity through action on the social determinants of health. Lancet. 2008; 372(9650): 1661-1669.

9. Katz AS, Pronk NP, McLellan D, Dennerlein J, Katz JN. Perceived workplace health and safety climates: Associations with worker outcomes and productivity. Am J Prevent Med. 2019; 57(4): 487-494.

10. Waddell G, Burton AK. Is work good for your health and well-being?: The Stationery Office; 2006.

11. World Bank. Doing business 2019: Training for reform. 2019.

12. Hsiao C. Panel data analysis-advantages and challenges. Test. 2007; 16(1): 1-22.

13. Andreß H-J. The need for and use of panel data. IZA World Labor. 2017.

14. Lustig N. Investing in health for economic development. Report by the Mexican Commission on Macroeconomics and Health, 1st Edition, Mexico. 2004; 1-60.

15. Organization WH. A conceptual framework for action on the social determinants of health. 2010.

16. GENEIA. Social determinants of health: From insights to action making $\mathrm{SDoH}$ scalable with technology. United States: Geneia; 2019.

17. Healthy People 2020. Determinants of Health Washington, DC: Office of Disease Prevention and Health Promotion 2020;

https://www.healthypeople.gov/2020/about/foundati on-health-measures/Determinants-of-Health. 
18. Boyce T, Brown C. Economic and social impacts and benefits of health systems. 2019.

19. Pharr JR, Moonie S, Bungum TJ. The impact of unemployment on mental and physical health, access to health care and health risk behaviors. ISRN Publ Health. 2011; 2012(ID 483432): 1-12.
20. Marmot M, Wilkinson R. Social determinants of health: OUP Oxford; 2005.

21. Marmot M. Status syndrome: How your social standing directly affects your health: A\&C Black; 2005.

\section{SJAMAO}

Copyright: (C) 2021 The Author(s); This is an open-access article distributed under the terms of the Creative Commons Attribution License (http://creativecommons.org/licenses/by/4.0), which permits unrestricted use, distribution, and reproduction in any medium, provided the original work is properly cited.

Citation: Veisi M, Karimi F. Health and Ease of Doing Business Indices in the Eastern Mediterranean Region Based on the Panel Data. SJAMAO, 2021; 3(3): 1-6.

https://doi.org/10.47176/sjamao.3.3.1 